\title{
$\$$ Research Square

\section{Characterizing Tobacco and Marijuana Use Among Youth Experiencing Homelessness in a Midwestern City}

\section{Allison M. Glasser ( $\nabla$ glasser.24@osu.edu )}

The Ohio State University College of Public Health

\section{Alice Hinton}

The Ohio State University College of Public Health

\section{Amy Wermert}

The Ohio State University College of Public Health

Joseph Macisco

The Ohio State University College of Public Health

Julianna Nemeth

The Ohio State University College of Public Health

\section{Research Article}

Keywords: homelessness, youth, young adults, combustible, marijuana, poly-tobacco

Posted Date: September 15th, 2021

DOI: https://doi.org/10.21203/rs.3.rs-824818/v1

License: (9) This work is licensed under a Creative Commons Attribution 4.0 International License. Read Full License 


\section{Abstract}

\section{Background}

Cigarette smoking is three times more prevalent among youth experiencing homelessness compared with the general population. Co-use of tobacco and marijuana is also common. The aim of this study is to characterize tobacco and marijuana use among homeless young people in a Midwestern city.

\section{Methods}

This study included 96 youth and young adults (52\% male, 39\% female, 5\% transgender/non-binary) attending a homeless drop-in center who had used at least one combustible tobacco product in the past week. We assessed past-month use of tobacco products and marijuana and other product use characteristics (e.g., frequency, brand and flavor).

\section{Results}

Most youth experiencing homelessness with past-week combustible tobacco use had used cigarettes (88.5\%), cigars (92.7\%), and marijuana (85.4\%) in the past month. One-third used electronic vapor products, $19.8 \%$ smoked hookah, and $11.5 \%$ used smokeless tobacco. Most marijuana users coadministered with tobacco (69.8\%). Daily combustible tobacco smoking was associated with having a child and smoking out of boredom/habit. Daily marijuana use was associated with using substances to cope with one's housing situation. Newport and Black \& Mild were the most popular brands of cigarettes and cigars. Most non-combustible tobacco users reported not having a usual brand. Cigar smokers reported the most varied selection of flavors.

\section{Conclusions}

Young combustible tobacco users experiencing homelessness engage in high-risk use patterns, including poly-tobacco use, co-use of tobacco with marijuana, and frequent combustible product use. Interventions that consider the full context of tobacco and marijuana use are needed to support cessation in this population.

\section{Background}

Cigarette smoking is about three times more prevalent among young people (ages 14 to 25 years) experiencing homelessness compared with the general population of youth and young adults $(1-3)$. Overall, combustible tobacco use, including cigarette and cigar smoking, constitutes the primary tobacco products used in this population (4). Additionally, electronic vapor products (EVPs) are used among young adults experiencing homelessness at nearly twice the rate and smokeless tobacco about five times the rate of use in the general population of young adults (5-7). Youth experiencing homelessness are primarily traditional combustible tobacco users or co-use cigarettes and cigars, however, poly-tobacco 
use is also prevalent particularly among those with substance use disorder and among those who have spent more nights outdoors (4).

Substance use (tobacco, alcohol, marijuana, methamphetamine, ecstasy, and inhalants) overall is extremely high among young people experiencing homelessness (8), with estimates up to $96 \%$ (9). Coadministration of tobacco and marijuana in particular is common among youth experiencing homelessness. A study of youth and young adults experiencing homelessness in Los Angeles (LA) County, California found that about $90 \%$ of tobacco users consumed tobacco and marijuana together (10), These users were heavier users of tobacco and marijuana compared to those who used tobacco alone or co-used, but not co-administered; they also tended to experience more severe homelessness and other risk factors like depression. Little cigars and cigarillos (LCCs) are commonly viewed among young adults experiencing homelessness as a discreet way to smoke marijuana (11). About three-quarters of cigar smoking high school youth in Cuyahoga County, Ohio in 2013 reported concurrent marijuana use, about half reported "freaking" their cigar (removing the filter paper from the cigar and repacking), and two-thirds reported using blunts (removing tobacco contents from a cigar and replacing or mixing with marijuana) (12).

Marijuana and tobacco are often used to cope with stress and traumatic events, which are common among young people experiencing homelessness $(13,14)$. A study of homeless smokers found that a large proportion had experienced trauma and reported posttraumatic stress symptoms; these individuals endorsed smoking to reduce negative affect and for the positive social effects (15). Tobacco use is socially acceptable and rather ubiquitous in homeless drop-in facilities and shelters, facilitating continued smoking among those in attendance (14). These factors unique to the homeless experience create a physical and social environment where tobacco use is normal and even expected. Despite the high prevalence of tobacco use in this population, many youth experiencing homelessness are willing to quit smoking. One-fifth to one-third of tobacco product users among youth and young adults experiencing homelessness in LA County were willing to quit their product in 2018 (16). A previous analysis of qualitative data from the current study showed that while willingness to quit is high, many youth experiencing homelessness are not successful at quitting and have limited access to support (17).

Much remains to be understood about tobacco and marijuana use among young people experiencing homelessness. The aim of this study is to characterize tobacco and marijuana use among young people experiencing homelessness in a Midwestern city, including frequency of product use and brand and flavor preferences. This information will help us to better understand patterns of use and inform future smoking cessation interventions.

\section{Methods}

\section{Participants}


Participants were youth and young adults experiencing homelessness in a Midwestern city attending a drop-in center. A total of 139 participants were recruited for this study. Participants were eligible if they had used at least one combustible tobacco product in the past week, were not currently making an attempt to quit smoking, were attending a drop-in center, and had not participated in an earlier phase of this study. Thirty-one participants were ineligible, ten participants refused, and two participants partially completed the survey and were excluded due to unreliable responses. The final sample consisted of 96 youth and young adults experiencing homelessness who consented to participate and completed the survey. This project was approved by The Ohio State University's Institutional Review Board.

\section{Measures}

\section{Demographic Characteristics}

We measured participants' age, gender (male, female, genderqueer, intersex, transgender female, transgender male, transgender, other), sexual orientation (heterosexual/straight, gay, lesbian, bisexual, queer/questioning, asexual, other), race (American Indian or Alaska Native, Asian, Black or African American, Native American, Native Hawaiian or another Pacific Islander, White, bi- or multi-racial, other), Hispanic ethnicity, education (less than high school, high school diploma, general educational development (GED), more than high school), number of children, pregnancy status for youth assigned female at birth, hours worked per week, and location slept most nights.

\section{Ever and Past 30-Day Tobacco Product and Marijuana Use}

We measured ever use and past 30-day frequency of use ( 0 days, $1-2$ days, $3-5$ days, $6-9$ days, $10-19$ days, 20-29 days, all 30 days) of the following products: cigarettes, cigars, hookah, EVPs, smokeless tobacco, and marijuana.

\section{Usual Brand and Flavor}

We asked participants if they have a usual brand for each product (excluding marijuana) (yes/no; asked of participants who had ever used that product), what that brand is, and whether that brand is usually flavored. Flavor categories were menthol or mint, clove or spice, fruit, chocolate, an alcoholic drink (such as wine, cognac, margarita, piña colada, peach schnapps, or other cocktails), candy or sweets, tobacco, coffee, vanilla, cola, or other (18).

\section{Marijuana Administration and Lifetime Use Frequency}

Among past 30-day marijuana users (at least once in the past 30 days), we measured the usual method of administration (blunt [cigar hallowed out and filled with marijuana]; joint, bong, pipe; spliff [combination of tobacco and marijuana]; food; drink; vaporized; some other way). We also asked participants how many times they have used marijuana in their lifetime $(0,1-2,3-9,10-19,20-39,40-$ 99 , and $100+$ times).

\section{Other Tobacco and Psychosocial Variables}


We assessed a number of tobacco-related and psychosocial factors that may be related to tobacco use and to homeless experiences. The details of these measures are provided in Supplemental Table 1. Briefly, we assessed tobacco dependence using the Hooked on Nicotine Checklist (HONC; 10-item instrument to identify signals of loss of autonomy among adolescents) (19), first use of tobacco (product, age), and motivations, temptations, and rewards from smoking $(20,21)$, and alcohol use. In addition, interoceptive awareness, coping, anger, and worry scales were assessed (22-25).

\section{Data Analyses}

Categorical variables are summarized with frequencies and percentages while continuous and ordinal variables are summarized with means and standard deviations or medians and interquartile ranges (IQR), as is appropriate based on the distribution of the variable. Fisher exact tests, $t$ tests, and Wilcoxon ranksum tests were conducted to examine group differences between: 1) daily combustible tobacco users vs. non-daily combustible users, and 2) daily marijuana users vs. non-daily marijuana users. Multivariable logistic regression models were fit to determine independent predictors of daily combustible use and separately, among the subset of current marijuana users, daily marijuana use. Stepwise selection was used to determine the terms included in the final models. All analyses were conducted in SAS 9.4 (SAS Institute Inc., Cary, NC), and p-values $<0.05$ were significant.

\section{Results}

\section{Sample Characteristics}

Participants were mostly young adults aged $18-24$ years $(n=93,97 \%)$, identified as male $(n=53,55 \%)$, heterosexual $(n=71,74 \%)$, Black $(n=51,53 \%)$ or multi-racial $(n=27,28 \%)$, non-Hispanic $(n=88,92 \%)$, and had earned a high school diploma $(n=46,48 \%)$ or less than high school $(n=31,32 \%)$ (Table 1$)$. Slightly more than one-third had children, and about half were unemployed. Participants were relatively evenly split between sleeping at a friend's house or own home, at the shelter or drop-in center, or outside on most nights. Participants were, on average, moderately dependent on nicotine. 
Table 1

Demographic and Tobacco Use Characteristics of Homeless Youth and Young Adults

\begin{tabular}{|c|c|c|}
\hline & $N=96$ & \\
\hline & $n$ & $\%$ \\
\hline \multicolumn{3}{|l|}{ Age } \\
\hline $14-17$ & 3 & $3 \%$ \\
\hline $18-24$ & 93 & $97 \%$ \\
\hline Age (mean, SD) & 21.82 & 2.00 \\
\hline \multicolumn{3}{|l|}{ Gender ${ }^{a}$} \\
\hline Male & 52 & $54 \%$ \\
\hline Female & 39 & $41 \%$ \\
\hline Transgender Female & 2 & $2 \%$ \\
\hline Transgender Male & 2 & $2 \%$ \\
\hline Non-binary & 1 & $1 \%$ \\
\hline \multicolumn{3}{|l|}{ Sexual Orientation ${ }^{\mathrm{b}}$} \\
\hline Heterosexual/Straight & 71 & $74 \%$ \\
\hline Bisexual & 19 & $20 \%$ \\
\hline Other & 6 & $6 \%$ \\
\hline \multicolumn{3}{|l|}{ Race } \\
\hline White & 15 & $16 \%$ \\
\hline Black & 51 & $53 \%$ \\
\hline Bi or Multi-racial & 27 & $28 \%$ \\
\hline Other & 3 & $3 \%$ \\
\hline \multicolumn{3}{|l|}{ Ethnicity } \\
\hline Non-Hispanic & 88 & $92 \%$ \\
\hline
\end{tabular}

a No participants identified as intersex or genderqueer, so they are not included

${ }^{\mathrm{b}}$ No participants identified as gay, lesbian, queer/questioning, or asexual, so they are not included

GED: General Education Development, SD: standard deviation, EVP: electronic vapor product, IQR: interquartile range, HONC: Hooked on Nicotine Checklist 


\begin{tabular}{|c|c|c|}
\hline \multirow[b]{2}{*}{ Hispanic } & \multicolumn{2}{|c|}{$N=96$} \\
\hline & 8 & $8 \%$ \\
\hline \multicolumn{3}{|l|}{ Education } \\
\hline Less than High School & 31 & $32 \%$ \\
\hline High School Diploma & 46 & $48 \%$ \\
\hline GED & 4 & $4 \%$ \\
\hline More than High School & 15 & $16 \%$ \\
\hline \multicolumn{3}{|l|}{ Children } \\
\hline None & 55 & $57 \%$ \\
\hline 1 or more & 41 & $43 \%$ \\
\hline \multicolumn{3}{|l|}{ Currently Pregnant } \\
\hline No & 36 & $86 \%$ \\
\hline Yes & 3 & $7 \%$ \\
\hline Don't Know & 3 & $7 \%$ \\
\hline \multicolumn{3}{|l|}{ Hours Work per Week } \\
\hline 0 & 50 & $52 \%$ \\
\hline $1-39$ & 20 & $21 \%$ \\
\hline$\geq 40$ & 24 & $25 \%$ \\
\hline \multicolumn{3}{|l|}{ Where Slept Most Nights } \\
\hline With family or friends / Own home & 31 & $32 \%$ \\
\hline Shelter / Drop-in-center & 27 & $28 \%$ \\
\hline $\begin{array}{l}\text { Group home / Treatment facility / Detention } \\
\text { facility }\end{array}$ & 13 & $14 \%$ \\
\hline Outside / Car / Tent & 25 & $26 \%$ \\
\hline
\end{tabular}

a No participants identified as intersex or genderqueer, so they are not included

${ }^{b}$ No participants identified as gay, lesbian, queer/questioning, or asexual, so they are not included

GED: General Education Development, SD: standard deviation, EVP: electronic vapor product, IQR: interquartile range, HONC: Hooked on Nicotine Checklist 


\begin{tabular}{|lll|}
\hline & N=96 \\
\hline Single Combustible & 10 & $11 \%$ \\
\hline Poly Combustible, no EVP/ST & 48 & $51 \%$ \\
\hline Combustible / EVP & 26 & $27 \%$ \\
\hline Combustible / ST & 3 & $3 \%$ \\
\hline Combustible / EVP/ ST & 8 & $8 \%$ \\
\hline Tobacco / Marijuana Use & & \\
\hline Tobacco Only & 14 & $15 \%$ \\
\hline Comb. / Marijuana & 48 & $50 \%$ \\
\hline Comb. / EVP / Marijuana & 24 & $3 \%$ \\
\hline Comb. / ST / Marijuana & 3 & $7 \%$ \\
\hline Comb. / EVP / ST / Marijuana & 7 & $(3.5-8)$ \\
\hline HONC (median, IQR) & 6 & $3 \%$ \\
\hline a No participants identified as intersex or genderqueer, so they are not included \\
\hline $\begin{array}{l}\text { b No participants identified as gay, lesbian, queer/questioning, or asexual, so they } \\
\text { are not included }\end{array}$ \\
\hline $\begin{array}{l}\text { GED: General Education Development, SD: standard deviation, EVP: electronic } \\
\text { vapor product, IQR: interquartile range, HONC: Hooked on Nicotine Checklist }\end{array}$ \\
\hline
\end{tabular}

\section{Ever and Past 30-Day (Current) Product Use \\ Combustible Tobacco}

Among the full sample, the most common product used was cigars, with $92.7 \%$ smoking cigars currently, only $5.2 \%$ having tried them but not currently using them, and $2.1 \%$ having never smoked them (Fig. 1 ). Closely following cigars, $88.5 \%$ smoked cigarettes currently, and equal proportions of the sample had ever smoked cigarettes (but did not currently smoke cigarettes) and had never smoked cigarettes (5.2\%). Most of the youth and young adults in our sample did not report currently smoking hookah (ever tried, but not currently smoking: $37.5 \%$, never tried hookah: $42.7 \%$ ), although about one-fifth of the sample did report currently smoking hookah (19.8\%).

\section{Non-Combustible Tobacco}

Seventy-two percent of youth and young adults in our sample ever used an EVP, while less than one-third (29.2\%) had ever used a smokeless tobacco product. Current use was lower where just over one-third of 
the youth and young adults in this study used EVPs and 11.5\% used smokeless tobacco in the past month (Fig. 1).

\section{Marijuana}

Most youth and young adults in the sample were currently using marijuana (85.4\% marijuana overall; 85.4\% blunts; Fig. 1). Thirty-four percent of the sample were currently using spliffs. Almost three-quarters (71.9\%) of the youth and young adults in this study reported having used marijuana more than 100 times in their lives, followed by $12.5 \%$ reporting 40-99 times and 5.2\% 20-39 times. Most marijuana users usually co-administered with tobacco, with $67.7 \%$ of our sample usually smoking blunts and $2.1 \%$ usually smoking spliffs. An additional 11.5\% reported usually smoking marijuana in a joint, bong or pipe, and $2.1 \%$ reported usually smoking marijuana in a bowl.

\section{Poly-Product Use}

The primary use patterns (Table 1) in the past month among youth and young adults experiencing homelessness in this sample was poly-combustible use (51\%) or combustible plus EVP use (27\%). Only $8 \%$ used all tobacco product types we assessed, and about $11 \%$ used just one combustible product. Few (3\%) used smokeless tobacco without EVPs.

Similar to strictly tobacco use patterns, about half of the sample reported concurrent use of combustible tobacco and marijuana, and about one quarter reported concurrent use of combustible tobacco, marijuana, and EVPs (Table 1). Fifteen percent used only tobacco with no marijuana, and $7 \%$ used all product types assessed.

\section{Frequency of Product Use in the Past 30 Days}

Combustible products (except hookah) were more frequently used than non-combustible products in this study. The most frequently used product in the past month among youth and young adults in our sample was cigarettes, with $40.6 \%$ reporting daily use (Fig. 2), followed by marijuana (27.1\%), cigars (18.8\%), and EVPs and smokeless tobacco (2.1\% each). No one reported daily hookah smoking. Infrequent use (1-2 days) was most common among cigar smokers (18.8\%), followed by EVPs (15.6\%), hookah (13.5\%), marijuana (8.3\%), smokeless tobacco (6.3\%), and cigarettes (4.2\%).

\section{Daily vs. Non-Daily Combustible Use}

We examined differences between daily and non-daily combustible tobacco users (Supplemental Table 2). Compared to non-daily combustible tobacco use, daily combustible tobacco use was associated with having at least one child (55.6\% vs. 31.4\%, $p=0.017)$, higher mean nicotine dependence as measured by the HONC (6.5 vs. 5.2, $p=0.039)$, past 30 -day cigarette smoking $(97.8 \%$ vs. $82.0 \%, p=$ $0.039)$, poly-combustible use $(60.0 \%$ vs. $42.0 \%, p=0.006)$, and younger mean age when first tried tobacco (13 years vs. 15 years, $p=0.028$ ). In addition, daily combustible tobacco users were more likely than nondaily users to endorse smoking for boredom relief $(p<0.001)$, stress relief $(p=0.025)$, or because it's 
comforting $(p=0.002)$, and smoking related to negative affect $(p=0.024)$ or habit $(p=0.001)$. More daily combustible tobacco users also reported binge drinking in the past month $(p=0.043)$.

In multivariable analyses (Table 2), significant predictors of daily tobacco use were having at least one child $(\mathrm{OR}=3.52,95 \% \mathrm{Cl}=1.25,9.92)$, smoking related to habit $(\mathrm{OR}=4.00,95 \% \mathrm{Cl}=1.08,14.83)$, smoking for boredom relief $(\mathrm{OR}=1.40,95 \% \mathrm{Cl}=1.14,1.71)$, and higher scores on the non-distracting scale of the Science of Behavior Change (SOBC) Assessment of Interoceptive Awareness (MAIA) measure (OR $=1.67$, $95 \% \mathrm{Cl}=1.10,2.54)$, indicating that those who tend not to ignore or distract oneself from sensations of pain or discomfort had higher odds of being a daily smoker.

Table 2

Multivariable logistic regression models assessing the relationship between tobacco/psychosocial factors and daily combustible/marijuana use

\begin{tabular}{|c|c|c|c|c|c|c|}
\hline \multirow[b]{2}{*}{ Psycho-Social Factors } & \multicolumn{3}{|c|}{$\begin{array}{l}\text { Daily (vs. Non-Daily) } \\
\text { Combustible }(n=45 ; 47 \%)\end{array}$} & \multicolumn{3}{|c|}{$\begin{array}{l}\text { Daily (vs. Non-Daily) } \\
\text { Marijuana }(n=26 ; 30 \%)\end{array}$} \\
\hline & OR & $95 \% \mathrm{Cl}$ & $\begin{array}{l}\mathrm{p} \\
\text { value }\end{array}$ & OR & $95 \% \mathrm{Cl}$ & $\begin{array}{l}\text { p } \\
\text { value }\end{array}$ \\
\hline$\geq 1$ child (vs. no children) & 3.52 & $\begin{array}{l}(1.25- \\
9.92)\end{array}$ & 0.017 & - & - & - \\
\hline $\begin{array}{l}\text { Situational Temptations Inventory: } \\
\text { Habit (1-unit increase) }\end{array}$ & 4.00 & $\begin{array}{l}(1.08- \\
14.83)\end{array}$ & 0.038 & - & - & - \\
\hline $\begin{array}{l}\text { Motivations for Smoking: Boredom } \\
\text { Relieve (1-unit increase) }\end{array}$ & 1.40 & $\begin{array}{l}(1.14- \\
1.71)\end{array}$ & 0.001 & - & - & - \\
\hline $\begin{array}{l}\text { SOBC MAIA: Non-Distracting (1-unit } \\
\text { increase) }\end{array}$ & 1.67 & $\begin{array}{l}(1.10- \\
2.54)\end{array}$ & 0.016 & - & - & - \\
\hline $\begin{array}{l}\text { Situational Temptations Inventory: } \\
\text { Negative Affect (1-unit increase) }\end{array}$ & - & - & - & 0.03 & $\begin{array}{l}(0.004- \\
0.21)\end{array}$ & 0.001 \\
\hline $\begin{array}{l}\text { SOBC Brief Cope: Substance (1-unit } \\
\text { increase) }\end{array}$ & - & - & - & 1.72 & $\begin{array}{l}(1.19- \\
2.48)\end{array}$ & 0.004 \\
\hline $\begin{array}{l}\text { Age First Tried Tobacco (5-unit } \\
\text { increase) }\end{array}$ & - & - & - & 0.25 & $\begin{array}{l}(0.10- \\
0.64)\end{array}$ & 0.004 \\
\hline
\end{tabular}

\section{Daily vs. Non-Daily Marijuana Use}

There were also differences between daily and non-daily marijuana users $(n=82)$. In univariable analyses (Supplemental Table 3), compared to non-daily marijuana users, daily marijuana users had lower mean nicotine dependence ( 4.7 vs. $6.4, p=0.017$ ) and were less likely to report that a combustible tobacco product was their first tobacco product tried ( $84.6 \%$ vs. $98.2 \%, p=0.048)$. Daily marijuana use was associated with reporting smoking (combustible tobacco) related to the positive social aspects $(p=$ 
$0.045)$, but less so when experiencing negative affect $(p=0.015)$ and because it is calming $(p=0.045)$. Daily marijuana use was associated with lower scores on the dysregulation scale of the SOBC Children's Emotion Management Scale (CEMS): Worry measure, indicating that daily marijuana users may selfregulate worry better than non-daily users $(p=0.045)$.

In multivariable analyses (Table 2), those who reported that they smoke combustible tobacco related to experiencing negative affect had lower odds $(\mathrm{OR}=0.03,95 \% \mathrm{Cl}=0.004,0.21)$ of daily marijuana use. The odds of being a daily marijuana user decreased by $75 \%$ for every five-year increase in age of first trial of tobacco $(p=0.004)$. Those who reported using substances to feel better about or get through one's housing situation had $72 \%$ higher odds of being a daily marijuana user $(p=0.004)$.

\section{Usual Brand and Flavor}

Most (89\%) cigarette smokers reported a usual brand (Supplemental Fig. 1). Almost three-quarters (73\%) of cigarette smokers reported that their usual brand was Newport, followed by Marlboro (6\%). The remainder of the brands reported made up $2 \%$ or less of cigarette smokers. Eighty-one percent of cigar smokers reported a usual brand. About half $(51 \%)$ of cigar smokers reported that their usual brand was Black \& Mild, followed by Swisher Sweets (16\%). The remainder of the brands reported made up $2 \%$ or less of cigar smokers. Most EVP users did not report a usual brand (72\%), $9 \%$ reported usually using JUUL, and $7 \%$ did not know what brand they usually used. Almost $60 \%$ of smokeless tobacco users did not report a usual brand. Twenty-five percent of smokeless tobacco users reported usually using Grizzly, $11 \%$ Copenhagen, and $7 \%$ other brands.

Among cigarette smokers who reported a usual brand $(n=81), 72.8 \%$ usually smoked a menthol or mint flavored brand (Supplemental Table 4). Cigar smokers reported the most varied selection of flavored products. About half of cigar smokers who report a usual brand $(n=76)$ use flavored products, ranging from $1.3 \%$ vanilla and coffee to $15.8 \%$ fruit. Almost all EVP users who reported a usual brand $(n=18)$ reported using flavored products; over half usually used fruit flavored EVPs. Most (75\%) of the smokeless tobacco users who had a usual brand $(n=12)$ used a menthol or mint flavor, while $25 \%$ used fruit flavors.

\section{Discussion}

The aim of this study was to characterize tobacco and marijuana use among young people experiencing homelessness in a Midwest city. Findings indicate that most (85\%) combustible tobacco users in our study currently used marijuana. This is consistent with another larger study of youth experiencing homelessness in LA County that found that $90 \%$ of any tobacco users were also using marijuana (10). Nationally among high school-aged youth, $53.6 \%$ of single tobacco product (cigarettes, cigars, smokeless tobacco) users and $64.5 \%$ of users of at least two tobacco products also used marijuana in the past month (26). Together, these studies suggest that co-use of marijuana is higher in youth and young adults experiencing homelessness than among the general population of young people. 
The vast majority of participants had used marijuana on 100 or more occasions in their lives (72\%). Although we did not measure past-month quantity of use, long-term data show that those who initiate marijuana use in adolescence and continue through young adulthood and use heavily have higher odds of negative health outcomes, such as substance or psychiatric problems, than non-users (27). We also found that $27 \%$ of our sample used marijuana daily in the past month and that daily use was associated with not smoking combustible tobacco due to negative affect, younger age of tobacco initiation, and using substances to cope with one's housing situation. Related to affect, evidence suggests that context matters - one study of young adults found that positive affect was related to lower odds of daily marijuana use among non-college students, but that negative affect was related to lower odds of daily marijuana use among college students (28). A systematic review of marijuana use concluded that earlier age of initiation of marijuana and initiating tobacco are associated with increased risk of later marijuana dependence (29). Given that homeless smokers initiate at a younger age, development of frequent marijuana use may be more likely in this population (30). Future research should assess frequency and quantity of marijuana use in relation to tobacco use among youth experiencing homelessness over time to better understand the health risks faced by this population.

Most smokers used marijuana through a blunt, co-administering with tobacco, with $85 \%$ of the sample reporting past-month use of blunts and $70 \%$ reporting usually smoking marijuana in blunt or a spliff. Another study in LA County found that $65 \%$ of current tobacco using youth and young adults experiencing homelessness co-administered tobacco and marijuana, which was associated with more frequent product use and often being around people who co-administer (10). Among young adults, coadministering tobacco and marijuana is associated with more frequent marijuana and tobacco use, use in greater quantity, and negative consequences due to marijuana use (e.g., missed an obligation, got into trouble, etc.) compared with exclusive users of each product type and users who sequentially use the products (31). More research is needed on the context of co-use among youth experiencing homelessness to address the psychosocial factors that influence these use patterns.

Using marijuana and tobacco together has been linked to development of nicotine and marijuana dependence, which could have implications for cessation intervention design (32). We did not assess interest in quitting smoking marijuana, and there is no evidence on marijuana cessation among youth experiencing homelessness. However, studies of adults and housing-secure individuals point to the need to address use of both products in smoking cessation studies. One study of tobacco Quitline callers found that of smokers who also reported currently using marijuana, $43 \%$ were interested in quitting marijuana in addition to tobacco (33). Another study of dual tobacco and marijuana users found compensation of one product when trying to quit the other, with $50 \%$ perceiving an increase in their marijuana smoking during tobacco cessation and $62 \%$ perceiving an increase in tobacco use during marijuana cessation (34). Some studies have found reduced tobacco cessation among marijuana users $(35,36)$. To develop cessation interventions for youth experiencing homelessness, targeting use of both tobacco and marijuana may be necessary. A meta-analysis of interventions targeting co-users found weak evidence for an effect on marijuana cessation and no clear effect on tobacco cessation (37). More 
research is needed to understand the relationship between use of combustible tobacco and marijuana and cessation of one product or both, especially among young people experiencing homelessness.

Poly-tobacco use was common in our study, with $89 \%$ reporting the use of a combustible product and at least one other product. Poly-tobacco use in the general population of youth and young adults is lower. In $2013,57.1 \%$ of youth and $65.2 \%$ of young adults used cigarettes and at least one other product in the past month (38). Across age groups in the same study, over $70 \%$ of past-month cigar smokers used at least one other tobacco product, and the predominant pattern of use was cigar and cigarette dual use (39). Although poly-tobacco use is high across all youth and young adults, with much fewer young people in the general population using tobacco compared with homeless youth, the burden of poly-tobacco use is greater among youth experiencing homelessness. Poly-tobacco use is associated with increased nicotine dependence (40), so may be necessary to address in smoking cessation interventions.

The most prevalent combination of products used in our study was two or more combustible products. In addition, combustible products (except hookah) were more frequently used than non-combustible products. This may be related to increased access due to reduced price and increased availability of cigars in particular (93\% of our sample smoked cigars in the past month), which are more likely to be sold in low-income neighborhoods $(41,42)$. Daily combustible tobacco use ( $47 \%$ of the sample) was associated with smoking out of habit or boredom, having at least one child, and tending not to ignore feelings of pain or discomfort. These findings are mostly consistent with other studies. A national study of young adults found that those who had at least one child were two times as likely to have ever smoked daily than those with no children (43), likely related to added stressors, especially for those without shelter. Other studies show that young adults who are novelty-seekers and who have more unorganized leisure time are more likely to be daily smokers $(43,44)$, which could indicate that providing structured activities, particularly in the context of time spent at a homeless drop-in center, could reduce frequent smoking.

The differences in patterns of use of combustible and non-combustible products in this study could also be due to attitudes and beliefs about product types. Youth experiencing homelessness have different perceptions of various non-cigarette tobacco products. A study found that perceptions of EVPs were generally negative due to their cost and a perception that EVPs may be just as harmful as cigarettes (11). Smokeless tobacco was also viewed negatively, as was snus, with homeless youth having mixed opinions about whether they are more or less harmful than regular cigarettes. These misperceptions could perpetuate the use of combustible products. It should be noted that our inclusion criteria included having used a combustible tobacco product in the past week, so the primary pattern of poly-combustible use and the difference in frequency of use of these products could be explained in part by this requirement.

Brand preferences were more common for cigarettes and cigars than for smokeless tobacco and EVPs. This may be related to less frequent use of non-combustible products in our study and thus less affiliation with a brand. Newport and Black \& Mild were the most popular cigarette and cigar brands, 
respectively. A national study of brand preferences among young adults found that while Marlboro was the most preferred brand, Newport was more preferred among Black, non-Hispanic and low-income young adults (45). In this same study, Swisher was the most preferred brand of cigar, followed by Black \& Mild. The dominance of Black \& Mild in our sample is somewhat surprising given that co-use of cigars with marijuana was so common, and Swishers are often the brand used to create blunts; however, Black \& Mild is preferred to smoke only tobacco $(46,47)$. Consistent with the popularity of Newport cigarettes, most (three-quarters) cigarette smokers usually smoked menthol cigarettes. Menthol cigarettes have been marketed heavily to disadvantaged groups, including young and Black consumers (48), so exposure to such marketing in our sample is likely. About half of cigar smokers usually use a flavored product, with fruit being the most popular, followed by alcoholic drink, and candy flavors, which is consistent with these flavors' share of the market nationally (49). Flavored use was also common among non-combustible tobacco users, with fruit flavors most popular among EVP users and menthol most popular among smokeless users, aligned with preferences in the general population of youth and young adults (50). Regulators should restrict sale and marketing of flavored tobacco use, particularly menthol in cigarettes and flavored cigars, which could make tobacco less appealing to homeless youth.

Data are available on tobacco and marijuana use prevalence among other samples of youth experiencing homelessness (10), but our study is one of the first to additionally assess flavor use, brands, and frequency of use among a sample of youth and young adults experiencing homelessness. However, there are several limitations to note. First, as our sample was a small convenience sample of youth and young adults experiencing homelessness in one drop-in center in one city, our results may not generalize to other geographic areas. Second, measures relied on self-report, so measurement error is possible. Third, another issue possibly affecting measurement is the difficulty in assessing cigars with only tobacco and blunts, which are often conflated (51). However, providing definitions in the survey questionnaire likely minimized this problem.

\section{Conclusions}

Young combustible tobacco users experiencing homelessness engage in high-risk use patterns, including poly-tobacco use, co-use of tobacco with marijuana, and frequent combustible product use. Interventions that consider the full context of tobacco and marijuana use are needed to support cessation in this population and to inform policy interventions that promote health equity.

\section{Abbreviations}

CEMS: Children's Emotion Management Scale

EVP: electronic vapor product

GED: general educational development

HONC: Hooked on Nicotine Checklist 
IQR: interquartile range

LA: Los Angeles

LCC: little cigars and cigarillos

SOBC: Science of Behavior Change

MAIA: Assessment of Interoceptive Awareness

\section{Declarations}

\section{Ethics approval and consent to participate}

This project was approved by The Ohio State University's Institutional Review Board.

\section{Consent for publication}

Not applicable.

\section{Availability of data and materials}

The datasets used and/or analysed during the current study are available from the corresponding author on reasonable request.

\section{Competing interests}

The authors declare that they have no competing interests.

\section{Funding}

This work was supported by the National Cancer Institute (NCI) grant 5K07CA216321 (PI: Nemeth J). This research was also supported by The Ohio State University Comprehensive Cancer Center and the National Institutes of Health under grant number P30 CA016058. Funding sources had no role in the study design, collection, analysis or interpretation of the data, writing the manuscript, or the decision to submit the paper for publication.

\section{Authors' contributions}

AG and JN conceived of the study. AH analyzed the data. AG wrote the first draft of the manuscript. All authors ( $A G, J N, A H, J M, A W$ ) interpreted the data and approved the final manuscript.

\section{Acknowledgements}

None. 
Not applicable.

\section{References}

1. Miech RA, Johnston LD, O'Malley PM, Bachman JG, Schulenberg JE, Patrick ME. Monitoring the Future national survey results on drug use, 1975-2018: Volume I, Secondary school students. Ann Arbor, MI: Institute for Social Research, The University of Michigan; 2019.

2. Wenzel SL, Tucker JS, Golinelli D, Green HD, Jr., Zhou A. Personal network correlates of alcohol, cigarette, and marijuana use among homeless youth. Drug and alcohol dependence. 2010;112(12):140-9.

3. Centers for Disease C, Prevention. Vital signs: current cigarette smoking among adults aged $>/=18$ years--United States, 2005-2010. MMWR Morb Mortal Wkly Rep. 2011;60(35):1207-12.

4. Golinelli D, Siconolfi D, Shadel WG, Seelam R, Tucker JS. Patterns of alternative tobacco product use among youth experiencing homelessness. Addict Behav. 2019;99:106088.

5. Mirbolouk M, Charkhchi P, Kianoush S, Uddin SMI, Orimoloye OA, Jaber R, et al. Prevalence and Distribution of E-Cigarette Use Among U.S. Adults: Behavioral Risk Factor Surveillance System, 2016. Annals of internal medicine. 2018;169(7):429-38.

6. Tucker JS, Shadel WG, Golinelli D, Ewing B. Alternative tobacco product use and smoking cessation among homeless youth in los angeles county. Nicotine \& tobacco research : official journal of the Society for Research on Nicotine and Tobacco. 2014;16(11):1522-6.

7. Jones DM, Majeed BA, Weaver SR, Sterling K, Pechacek TF, Eriksen MP. Prevalence and Factors Associated with Smokeless Tobacco Use, 2014-2016. Am J Health Behav. 2017;41(5):608-17.

8. Santa Maria D, Padhye N, Yang Y, Gallardo K, Santos GM, Jung J, et al. Drug use patterns and predictors among homeless youth: Results of an ecological momentary assessment. Am J Drug Alcohol Abuse. 2018;44(5):551-60.

9. Bousman CA, Blumberg EJ, Shillington AM, Hovell MF, Ji M, Lehman S, et al. Predictors of substance use among homeless youth in San Diego. Addict Behav. 2005;30(6):1100-10.

10. Tucker JS, Shadel WG, Seelam R, Golinelli D, Siconolfi D. Co-use of tobacco and marijuana among young people experiencing homelessness in Los Angeles County. Drug and alcohol dependence. 2020;207:107809.

11. Shadel WG, Tucker JS, Abbott MM. Knowledge of Alternative Tobacco Products in Unaccompanied Homeless Youth. Tob Regul Sci. 2019;5(1):65-75.

12. Trapl ES, Koopman Gonzalez SJ, Cofie L, Yoder LD, Frank J, Sterling KL. Cigar Product Modification Among High School Youth. Nicotine \& tobacco research : official journal of the Society for Research on Nicotine and Tobacco. 2018;20(3):370-6. 
13. DiGuiseppi GT, Davis JP, Christie NC, Rice E. Polysubstance use among youth experiencing homelessness: The role of trauma, mental health, and social network composition. Drug and alcohol dependence. 2020;216:108228.

14. Pratt R, Pernat C, Kerandi L, Kmiecik A, Strobel-Ayres C, Joseph A, et al. "It's a hard thing to manage when you're homeless": the impact of the social environment on smoking cessation for smokers experiencing homelessness. BMC public health. 2019;19(1):635.

15. Baggett TP, Campbell EG, Chang Y, Magid LM, Rigotti NA. Posttraumatic Stress Symptoms and Their Association With Smoking Outcome Expectancies Among Homeless Smokers in Boston. Nicotine \& tobacco research : official journal of the Society for Research on Nicotine and Tobacco. 2016;18(6):1526-32.

16. Tucker JS, Shadel WG, Golinelli D, Ewing B, Mullins L. Motivation to Quit and Interest in Cessation Treatment Among Homeless Youth Smokers. Nicotine \& tobacco research : official journal of the Society for Research on Nicotine and Tobacco. 2015;17(8):990-5.

17. Glasser AM, Macisco JM, Miller LM, Garbsch EM, Wermert A, Nemeth JM. Smoking cessation methods among homeless youth in a Midwestern city. Addict Behav Rep. 2020;11:100276.

18. Centers for Disease Control and Prevention. Youth Risk Behavior Survey Questionnaire 2019 [Available from: www.cdc.gov/yrbs.

19. DiFranza JR, Savageau JA, Fletcher K, Ockene JK, Rigotti NA, McNeill AD, et al. Measuring the loss of autonomy over nicotine use in adolescents: the DANDY (Development and Assessment of Nicotine Dependence in Youths) study. Arch Pediatr Adolesc Med. 2002;156(4):397-403.

20. Plummer BA, Velicer WF, Redding CA, Prochaska JO, Rossi JS, Pallonen UE, et al. Stage of change, decisional balance, and temptations for smoking: measurement and validation in a large, schoolbased population of adolescents. Addict Behav. 2001;26(4):551-71.

21. Wills TA, Sandy JM, Shinar O. Cloninger's constructs related to substance use level and problems in late adolescence: a mediational model based on self-control and coping motives. Exp Clin Psychopharmacol. 1999;7(2):122-34.

22. Carver CS, Scheier MF, Weintraub JK. Assessing coping strategies: a theoretically based approach. J Pers Soc Psychol. 1989;56(2):267-83.

23. Mehling WE, Price C, Daubenmier JJ, Acree M, Bartmess E, Stewart A. The Multidimensional Assessment of Interoceptive Awareness (MAIA). PLoS One. 2012;7(11):e48230.

24. Zeman JL, Cassano M, Suveg C, Shipman K. Initial validation of the children's worry management scale. Journal of Child and Family Studies. 2010;19(4):381-92.

25. Zeman JL, Shipman K, Penza-Clyve S. Development and initial validation of the Children's Sadness Management Scale. Journal of Nonverbal Behavior. 2001;25(3):187-205.

26. Creamer MR, Portillo GV, Clendennen SL, Perry CL. Is Adolescent Poly-tobacco Use Associated with Alcohol and Other Drug Use? Am J Health Behav. 2016;40(1):117-22.

27. Terry-McElrath YM, O'Malley PM, Johnston LD, Bray BC, Patrick ME, Schulenberg JE. Longitudinal patterns of marijuana use across ages 18-50 in a US national sample: A descriptive examination of 
predictors and health correlates of repeated measures latent class membership. Drug and alcohol dependence. 2017;171:70-83.

28. Patrick ME, Yeomans-Maldonado G, Griffin J. Daily Reports of Positive and Negative Affect and Alcohol and Marijuana Use Among College Student and Nonstudent Young Adults. Substance use \& misuse. 2016;51(1):54-61.

29. National Academy of Sciences, Engineering and Medicine (NASEM). The Health Effects of Cannabis and Cannabinoids: The Current State of Evidence and Recommendations for Research. The National Academies Collection: Reports funded by National Institutes of Health. Washington (DC)2017.

30. Butler J, Okuyemi KS, Jean S, Nazir N, Ahluwalia JS, Resnicow K. Smoking characteristics of a homeless population. Subst Abus. 2002;23(4):223-31.

31. Tucker JS, Pedersen ER, Seelam R, Dunbar MS, Shih RA, D'Amico EJ. Types of cannabis and tobacco/nicotine co-use and associated outcomes in young adulthood. Psychol Addict Behav. 2019;33(4):401-11.

32. Agrawal A, Budney AJ, Lynskey MT. The co-occurring use and misuse of cannabis and tobacco: a review. Addiction (Abingdon, England). 2012;107(7):1221-33.

33. Carpenter KM, Torres AJ, Salmon EE, Carlini BH, Vickerman KA, Schauer GL, et al. Marijuana Use and Adherence to Smoking Cessation Treatment Among Callers to Tobacco Quitlines. Prev Chronic Dis. 2020;17:E102.

34. McClure EA, Tomko RL, Salazar CA, Akbar SA, Squeglia LM, Herrmann E, et al. Tobacco and cannabis co-use: Drug substitution, quit interest, and cessation preferences. Exp Clin Psychopharmacol. 2019;27(3):265-75.

35. Rogers AH, Shepherd JM, Buckner JD, Garey L, Manning K, Orr MF, et al. Current cannabis use and smoking cessation among treatment seeking combustible smokers. Drug and alcohol dependence. 2020;209:107928.

36. Voci S, Zawertailo L, Baliunas D, Masood Z, Selby P. Is cannabis use associated with tobacco cessation outcome? An observational cohort study in primary care. Drug and alcohol dependence. 2020;206:107756.

37. Walsh $\mathrm{H}$, McNeill A, Purssell E, Duaso M. A systematic review and Bayesian meta-analysis of interventions which target or assess co-use of tobacco and cannabis in single- or multi-substance interventions. Addiction (Abingdon, England). 2020;115(10):1800-14.

38. Taylor KA, Sharma E, Edwards KC, Halenar MJ, Kissin W, Kasza KA, et al. Longitudinal pathways of exclusive and polytobacco cigarette use among youth, young adults and adults in the USA: findings from the PATH Study Waves 1-3 (2013-2016). Tobacco control. 2020;29(Suppl 3):s139-s46.

39. Edwards KC, Sharma E, Halenar MJ, Taylor KA, Kasza KA, Day H, et al. Longitudinal pathways of exclusive and polytobacco cigar use among youth, young adults and adults in the USA: findings from the PATH Study Waves 1-3 (2013-2016). Tobacco control. 2020;29(Suppl 3):s163-s9.

40. Harrell PT, Naqvi SMH, Plunk AD, Ji M, Martins SS. Patterns of youth tobacco and polytobacco usage: The shift to alternative tobacco products. Am J Drug Alcohol Abuse. 2017;43(6):694-702. 
41. Giovenco DP, Spillane TE, Merizier JM. Neighborhood Differences in Alternative Tobacco Product Availability and Advertising in New York City: Implications for Health Disparities. Nicotine \& tobacco research : official journal of the Society for Research on Nicotine and Tobacco. 2019;21(7):896-902.

42. Cantrell J, Kreslake JM, Ganz O, Pearson JL, Vallone D, Anesetti-Rothermel A, et al. Marketing little cigars and cigarillos: advertising, price, and associations with neighborhood demographics. Am J Public Health. 2013;103(10):1902-9.

43. Hu MC, Davies M, Kandel DB. Epidemiology and correlates of daily smoking and nicotine dependence among young adults in the United States. Am J Public Health. 2006;96(2):299-308.

44. Kvaavik E, von Soest T, Pedersen W. Nondaily smoking: a population-based, longitudinal study of stability and predictors. BMC public health. 2014;14:123.

45. Glasser AM, Johnson AL, Rath JM, Williams VF, Vallone DM, Villanti AC. Tobacco Product Brand Preference Among US Young Adults, 2011-2014. Tob Regul Sci. 2016;2(1):44-55.

46. Giovenco DP, Spillane TE, Mauro CM, Martins SS. Cigarillo sales in legalized marijuana markets in the U.S. Drug and alcohol dependence. 2018;185:347-50.

47. Giovenco DP, Miller Lo EJ, Lewis MJ, Delnevo CD. "They're Pretty Much Made for Blunts": Product Features That Facilitate Marijuana Use Among Young Adult Cigarillo Users in the United States. Nicotine \& tobacco research : official journal of the Society for Research on Nicotine and Tobacco. 2017;19(11):1359-64.

48. Richardson A, Ganz O, Pearson J, Celcis N, Vallone D, Villanti AC. How the industry is marketing menthol cigarettes: the audience, the message and the medium. Tobacco control. 2015;24(6):594600 .

49. Delnevo CD, Giovenco DP, Ambrose BK, Corey CG, Conway KP. Preference for flavoured cigar brands among youth, young adults and adults in the USA. Tobacco control. 2015;24(4):389-94.

50. Rose SW, Johnson AL, Glasser AM, Villanti AC, Ambrose BK, Conway K, et al. Flavour types used by youth and adult tobacco users in wave 2 of the Population Assessment of Tobacco and Health (PATH) Study 2014-2015. Tobacco control. 2020;29(4):432-46.

51. Delnevo CD, Bover-Manderski MT, Hrywna M. Cigar, marijuana, and blunt use among US adolescents: Are we accurately estimating the prevalence of cigar smoking among youth? Prev Med. 2011;52(6):475-6.

\section{Figures}




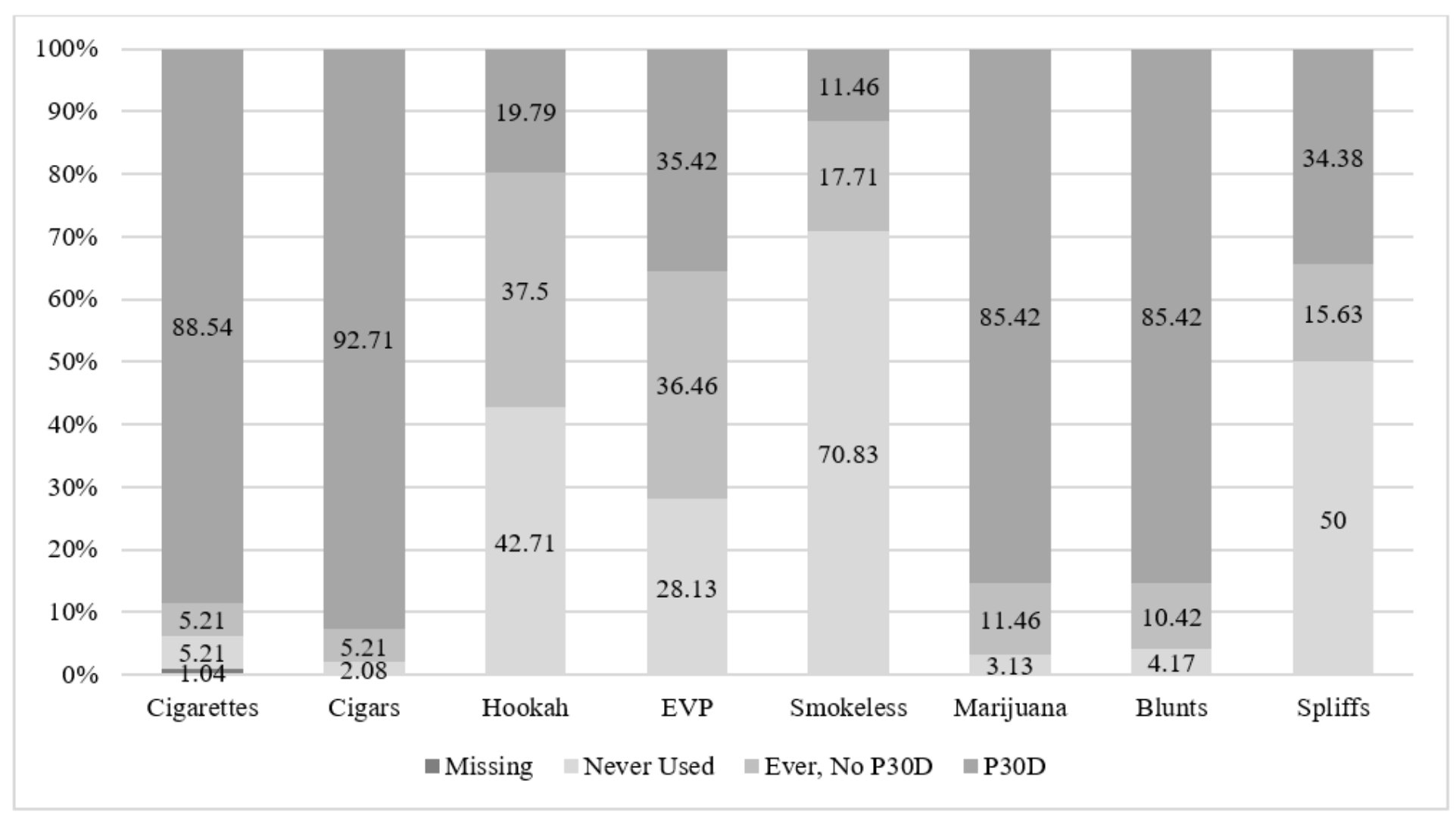

\section{Figure 1}

Never, Ever, and Past 30-Day Use of Tobacco Products and Marijuanaa a A blunt is a cigar hallowed out and filled with marijuana; a spliff is a combination of tobacco and marijuana EVP: electronic vapor product; P30D: past 30-day use 


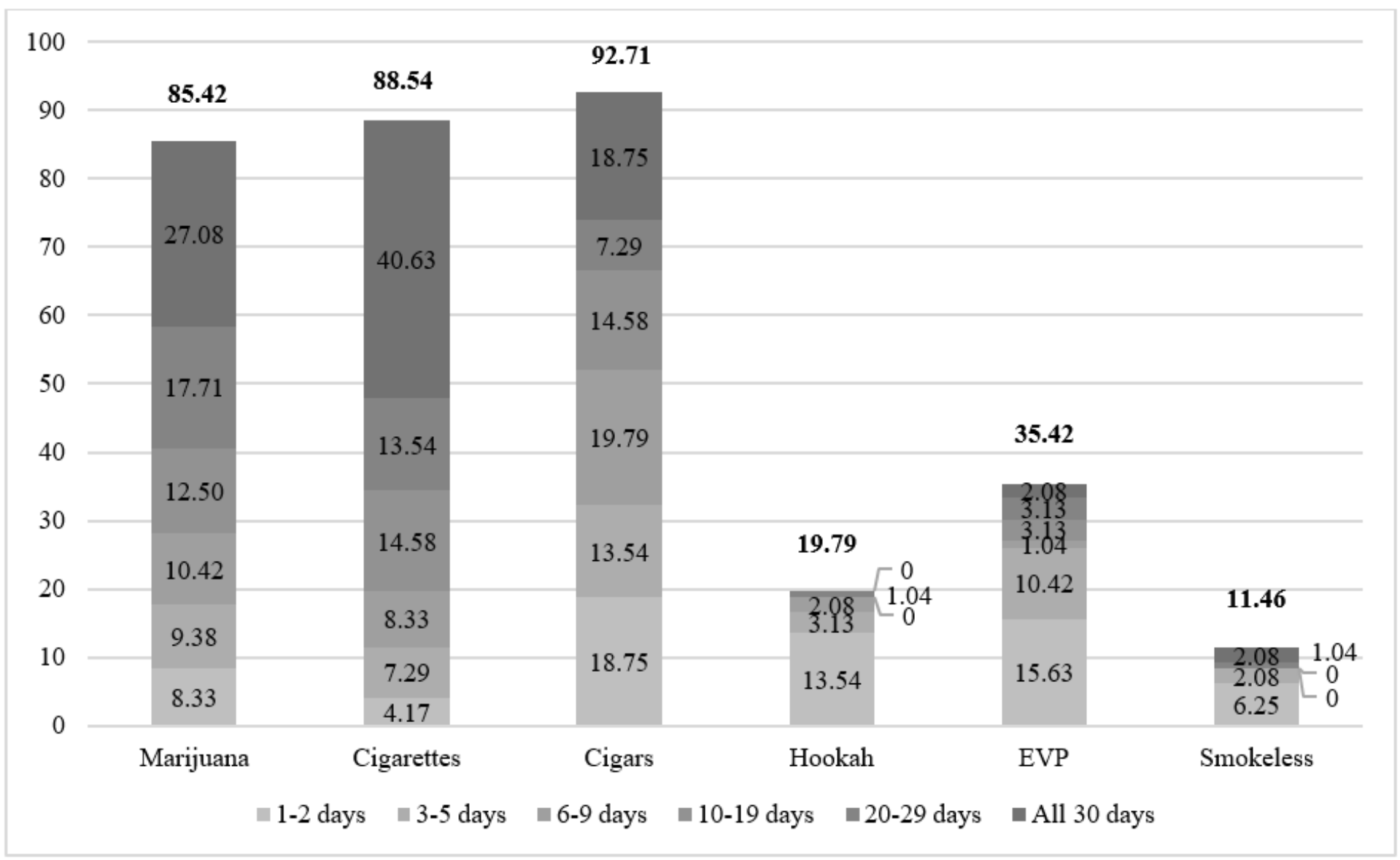

Figure 2

Past 30-Day Marijuana and Tobacco Product Use Frequency EVP: electronic vapor product

\section{Supplementary Files}

This is a list of supplementary files associated with this preprint. Click to download.

- SupplementalTables.docx

- SupplementalFigure.docx 